\title{
Segmented block copolymers based on polyamide-4,6 and poly(propylene oxide)
}

\author{
P. F. van Hutten, E. Walch, A. H. M. Veeken and R. J. Gaymans \\ University of Twente, Department of Chemical Technology, PO Box 217. \\ 7500 AE Enschede, The Netherlands \\ (Received 26 May 1989; accepted 17 July 1989)
}

\begin{abstract}
Segmented copolymers were obtained through copolymerization of polyamide- 4,6 and poly(propylene oxide) (PPOx). An amine-terminated PPOx ('soft') segment of molar mass 430 was reacted with nylon-4,6 salt in an autoclave $\left(30 \mathrm{~min}, 210^{\circ} \mathrm{C}, 7 \mathrm{bar}\right)$. In this reaction a prepolymer was prepared, which was postcondensed afterwards. In ethanol, a considerable amount of material could be extracted from the solid copolymers of low polyamide content. Extractability was found to be strongly reduced with increasing polyamide content, i.e. increasing length of the polyamide ('hard', crystallizable) segments. Torsional tests showed an extended rubber plateau of fairly constant modulus. Whereas PPOx has a $T_{\mathrm{g}}$ of $-60^{\circ} \mathrm{C}$, the $T_{\mathrm{g}}$ values of the copolymers were higher as a result of (i) the restricted length of the PPOx segments and (ii) dissolution of uncrystallized polyamide segments in the PPOx phase. The high melting point of polyamide- 4,6 was approached by the copolymer of high polyamide content, but the softer copolymers had lower melting points because of insufficient length of the polyamide segments.
\end{abstract}

(Keywords: segmented block copolymer; poly(ether amide); polyether; polyamide-4,6; nylon-4,6)

\section{INTRODUCTION}

Semicrystalline homopolymers of moderate crystallinity are characterized by a region of rubbery behaviour between the glass transition temperature and the melting point. Above $T_{\mathrm{g}}$, the crystallites serve as crosslinks between flexible chains, just like the chemical crosslinks in a conventional rubber. The difference is, however, that the crystallites are thermally labile and that the thermoplast can be melt-processed.

This paper focuses on thermoplastic elastomers (TPE). Their development started with pioneering work on polyurethanes at I.G. Farben (Germany) in the late $1930 s^{1}$. More insight into structure-property relationships of TPE was gained in the 1950s as a part of the development of polyester fibres ${ }^{2}$. The idea behind TPE is to extend the temperature range between $T_{\mathrm{g}}$ and $T_{\mathrm{m}}$, in order to obtain materials that are truly rubbery from room temperature (or below) up to a fairly high temperature (say $250^{\circ} \mathrm{C}$ ) and can be melt-processed at a somewhat higher temperature. Since thermoplasts usually satisfy the relation $T_{\mathrm{g}} / T_{\mathrm{m}} \simeq 0.6$ (temperature in kelvins), the above end is not likely to be attained for any homopolymer. One must therefore construct a block copolymer, the chains of which consist of two types of blocks, flexible (low- $T_{\mathrm{g}}$ ) ones and stiff, fast-crystallizing ones. These blocks are commonly referred to as 'soft' and 'hard' blocks, respectively. In the solid state such a copolymer shows a phase-separated morphology: hard, crystalline domains are more or less dispersed in an elastomeric matrix.

Hard blocks excluded from the crystalline domains might either be molecularly mixed with the soft blocks, or form a separate amorphous phase. The former case results in displacement of $T_{\mathrm{g}}$ to higher values, whereas a three-phase system shows multiple glass transitions. In copolymers obtained through condensation polymeriz- ation, block lengths have to be small, and so-called multiblock or 'segmented' TPE are obtained. Nonetheless, the solid copolymer has a microphase-separated structure, be it on a very fine scale. Examples of segmented TPE copolymers are: polyurethane ${ }^{3-5}$, poly(siloxane urea) ${ }^{6}$, copolyester and poly(ether ester) ${ }^{7-11}$ and poly(ether amide) $)^{12-16}$.

The aim of this investigation is to develop new types of TPE with a larger service temperature range, and thereby to enlarge the applicability of these materials. As indicated above, this comes down to extending the rubber region between $T_{\mathrm{g}}$ and $T_{\mathrm{m}}$. This is achieved by selecting a high-melting, fast-crystallizing hard block.

In view of our experience with polyamide-4,6 $\left(T_{\mathrm{m}} \simeq\right.$ $290^{\circ} \mathrm{C}$ ), which has been extensively studied in our laboratory ${ }^{17}$, we have chosen this polyamide to be the hard component in a number of different TPE. For this application, high crystallinity ( $>40 \%$ ) and high crystallization rate are distinct advantages of nylon- 4,6 over other polyamides.

In a previous research study, the TPE of nylon-4,6 and poly(tetramethylene oxide) (PTMO) soft segments was investigated ${ }^{18}$. In these copolymers the presence of two amorphous phases was evident from the occurrence of two glass transitions. One of these was found at an unfavourably high temperature of $50-80^{\circ} \mathrm{C}$, and attributed to a mixed phase containing polyamide as the major component. Moreover, many of the copolymer preparations proved to be molecularly inhomogeneous. A substantial mass fraction of the material was found to be extractable in ethanol, the extract containing copolymer of very low polyamide content. This was ascribed to melt phasing during the polymerization reaction (which was carried out in an autoclave).

As an alternative, we have prepared poly(ether amides) with poly(propylene oxide) (PPOx) instead of PTMO as 
the soft segment. Commercially obtainable PPOx oligomers are said to have a narrower chain-length distribution than PTMO oligomers ${ }^{10}$. TPE based on nylon4,6 (N46) and PPOx will be the subject of this paper.

\section{EXPERIMENTAL}

\section{Materials and copolymer synthesis}

The synthesis of N46-PPOx copolymers is carried out in two steps: first a prepolymer is prepared, which is postcondensed afterwards in order to increase the molar mass.

The prepolymer syntheses were carried out in a 1.4 litre autoclave (Juvo 142) equipped with anchor stirrer and heating device.

We used commercial PPOx diamines (Jeffamine D-400 and Jeffamine D-2000 from Texaco Chemical Co) as starting substances. These are oligoethers capped with an amino group at both ends of the chain:<smiles>CC(N)COCC(C)N</smiles>

The molar masses amounted to 430 and 2090 , respectively, as determined by amino end-group analysis.

Along with the PPOx diamine, a stoichiometric amount of adipic acid (Merck, Pure Food Grade) was added in order to have the right functionality for copolymerization with the nylon $-4,6$ blocks.

Nylon-4,6 was added in the form of the salt, which was prepared from adipic acid and 1,4-diaminobutane (Merck, Synthetic Grade, distilled) as described previously ${ }^{17}$.

The total mass of the reaction mixture amounted to $\sim 100 \mathrm{~g}$. In order to reduce the tendency to phasing, $m$-cresol was added to the reaction mixture in amounts of $1 \mathrm{ml}$ per gram of reactants.

The reaction was carried out at $210^{\circ} \mathrm{C}$ for $30 \mathrm{~min}$, in which time a maximum pressure of about 7 bar was attained. At the end of the reaction period the pressure was released and the temperature was raised to $260^{\circ} \mathrm{C}$ in order to have water and $m$-cresol evaporate from the mixture $(1 \mathrm{~h})$.

Postcondensation took place in a rotating glass vessel situated in an oven. The finely divided prepolymer (milled autoclave product) was kept in a stream of dry nitrogen at $260^{\circ} \mathrm{C}$ for $24 \mathrm{~h}$.

\section{Characterization}

Viscometry. The inherent viscosity of $1 \mathrm{~g} \mathrm{dl}^{-1}$ solutions of copolymer in $m$-cresol was measured in an Ubbelohde viscometer at $25^{\circ} \mathrm{C}$.

End-group analysis. The concentration of amine endgroups was determined by potentiometric titration of a $100-150 \mathrm{mg}$ sample in $35 \mathrm{ml} 85 \%$ phenol, the reagent being $0.1 \mathrm{M}$ trifluoromethanesulphonic acid in t-butanol. Carboxylic acid end-groups in a 100-150 mg sample were measured potentiometrically in a mixture of $3 \mathrm{~g} o$-cresol and $35 \mathrm{ml}$ benzyl alcohol, with $0.1 \mathrm{M} \mathrm{KOH}$ in t-butanol.

Compression moulding. Test specimens were meltpressed in a simple mould kept between the heating plates of a hydraulic press (Lauffer). The copolymer grains were compressed and kept at a temperature $20-30^{\circ} \mathrm{C}$ above the melting point for $\sim 5 \mathrm{~min}$, after which water cooling of the heating plates was started.

Ethanol extraction. A Soxhlet apparatus was used to extract the ethanol-soluble material from compressionmoulded bars. Extraction was continued for $16-18 \mathrm{~h}$.

Differential scanning calorimetry. D.s.c. measurements were carried out with a DuPont 990 Thermal Analyzer. The scales of temperature as well as heat flux were calibrated by using an indium standard. The sample compartment was purged with nitrogen. Sample weights varied between 5 and $10 \mathrm{mg}$ and open sample containers were employed.

The usual procedure for postcondensed copolymer grains was as follows:

(i) first heating run at $20^{\circ} \mathrm{C} \mathrm{min}^{-1}$ up to $20^{\circ} \mathrm{C}$ above $T_{m}$;

(ii) equilibration for $5 \mathrm{~min}$ at the latter temperature;

(iii) cooling run at $10^{\circ} \mathrm{C} \mathrm{min}-1$ down to $150^{\circ} \mathrm{C}$ below $T_{\mathrm{m}}$;

(iv) second heating run at $20^{\circ} \mathrm{C} \mathrm{min}^{-1}$.

Baselines for melting endotherms and crystallization exotherms were found by linear extrapolation of a straight portion of the d.s.c. trace on the high-temperature side of the peak. Although this procedure does not take into account any difference in specific heat between solid and melt, it could be carried out with little ambiguity in most cases.

Torsional modulus. A computer-controlled Myrenne torsion pendulum was employed. Samples of approximate dimensions $50 \times 9 \times 2 \mathrm{~mm}$ were machined from compression-moulded bars and dried in vacuum at $110^{\circ} \mathrm{C}$ for $16 \mathrm{~h}$ prior to testing. The computer calculated storage and loss moduli from damped oscillations at a frequency of $1 \mathrm{~Hz}$, while the sample was continuously heated from $-150^{\circ} \mathrm{C}$ to the onset of melting (flow) at a rate of $\sim 1^{\circ} \mathrm{C} \mathrm{min}^{-1}$.

Wide-angle $X$-ray diffraction. WAXD photographs were obtained in a Kiessig flat-plate camera. Ni-filtered $\mathrm{Cu} \mathrm{K} \alpha$ radiation was obtained from a Philips generator operated at $35 \mathrm{kV}$ and $25 \mathrm{~mA}$.

Compression-moulded samples of $2 \mathrm{~mm}$ thickness were dried in vacuum at $110^{\circ} \mathrm{C}$ prior to mounting. Exposure in the evacuated camera took $6-8 \mathrm{~h}$, at a sample-to-film distance of $38.5 \mathrm{~mm}$.

The optical transmission of the photographs was recorded with a Nonius densitometer.

Small-angle $X$-ray scattering. SAXS measurements were carried out by means of a Kratky camera (model 1970) equipped with a step-scanning device. Cu K $\alpha$ radiation $(\lambda=0.1542 \mathrm{~nm})$ was produced by a Philips generator operated at $45 \mathrm{kV}$ and $45 \mathrm{~mA}$. Monochromatization was achieved by using a $\mathrm{Ni}$ filter in combination with pulse-height discrimination of the detector signal.

Sample thickness amounted to $\sim 1.5 \mathrm{~mm}$, and the length of the sample in the X-ray beam was sufficient for the infinite-slit assumption to be valid. The angular scan ranged from $s=0.009$ to $0.45 \mathrm{~nm}^{-1}(s=2 \sin \theta / \lambda)$. Scattering curves were corrected for parasitic scattering. They were put on an absolute scale by means of a Lupolen calibration sample and by correcting for sample thickness and absorption.

Long-period values were calculated from desmeared 
and Lorentz-corrected scattering data by application of Bragg's formula. Implicit in this procedure is the assumption that scattering is produced by lamellar stacks.

All calculations were done by means of the well known computer program by Vonk ${ }^{19}$.

\section{REMARKS ON BLOCK LENGTH AND POLYAMIDE CONTENT}

In polycondensation, the reactivity of a monomer is usually not dependent on its size, and the products obtained from monomer mixtures have the properties expected for random copolymers, such as intermediate values of the elastic modulus. Block formation is purely statistical in a homogeneous reaction mixture. Phase separation of the reactants, on the other hand, will lead to pronounced blockiness or even separate homopolymers being formed.

In the paper by Frensdorff ${ }^{20}$ it is demonstrated that random copolymerization leads to a very broad distribution of block lengths. This must be borne in mind when one considers properties that depend on the number of hard domains (crystallites) and/or their size, e.g. melting temperature. In pure nylon-4,6 a crystallite thickness of $7 \mathrm{~nm}$, which corresponds to approximately five repeat units, yields a melting temperature of $290^{\circ} \mathrm{C}$.

The polyamide content $w_{\mathrm{PA}}$ (mass fraction) of a copolymer is defined such that each amide bond is included. This is accomplished by putting:

$$
w_{\mathrm{PA}}+w_{\mathrm{PEth}}=1
$$

in which $w_{\text {PEth }}$ refers to the polyether part of the PPOx diamine segments; the - NH-groups are excluded. These amine groups are thus included in the value of $w_{\mathrm{PA}}$. The copolymer that was obtained from PPOx diamine and adipic acid, being a true polyamide, is rightly characterized by a positive value of $w_{\mathrm{PA}}$. For pure nylon-4,6, $w_{\mathrm{PA}}=1$.

\section{RESULTS AND DISCUSSION}

\section{Characterization of as-prepared copolymers}

The prepolymers obtained from the autoclave syntheses were varying in colour from beige to pale yellow. After postcondensation, the material's appearance had become much darker, varying from orange brown to dark brown.

When PPOx of molar mass 2090 was employed in the copolymerization, the solids produced were inhomogeneous. We have ascribed this to a macroscopic phase separation in the reaction mixture, resulting in a crude morphology of the solid. These materials will not be discussed further in this paper.

Solution viscosity measurements and end-group analysis served to characterize the overall result of the copolymer syntheses. The results for copolymers based on PPOx of molar mass 430 are contained in Table 1. Potentiometric titration of end-groups showed that excess acid was present in the samples investigated. This resulted in low values of the number-average molar mass. Another indication of low molar mass was found in the values of the inherent viscosity. Obviously, there has been an imbalance regarding the stoichiometry of the reactants. This is attributed to uncertainties in functionality and molar mass of the PPOx diamine starting material. Moreover, evaporation of diaminobutane may have played a role. This has been found to take place in the polycondensation of nylon- $4,6^{17}$. In order to compensate for this, we have employed slightly basic nylon salt in our syntheses (a $1 \%$ aqueous solution of the salt has a $\mathrm{pH}$ of 7.8), but apparently this has not been an adequate measure.

\section{Ethanol extraction}

Pure PPOx is soluble in water and in ethanol. The poly(ether amide) prepared from PPOx diamine and adipic acid (sample PA26) proved to be completely soluble too. It is therefore expected that, in the case of N46-PPOx copolymers, those chains which are not anchored in the polyamide crystallites will be extractable in ethanol. The hard-block content or the length of the hard blocks in these chains may be insufficient for taking part in crystallization.

Compression-moulded samples were subjected to Soxhlet extraction with ethanol for $16 \mathrm{~h}$. The results are contained in Table 1 and shown in Figure 1. The mass fraction of extractable material is plotted vs. the average polyamide content, $w_{\mathrm{PA}}$. The extract was not analysed

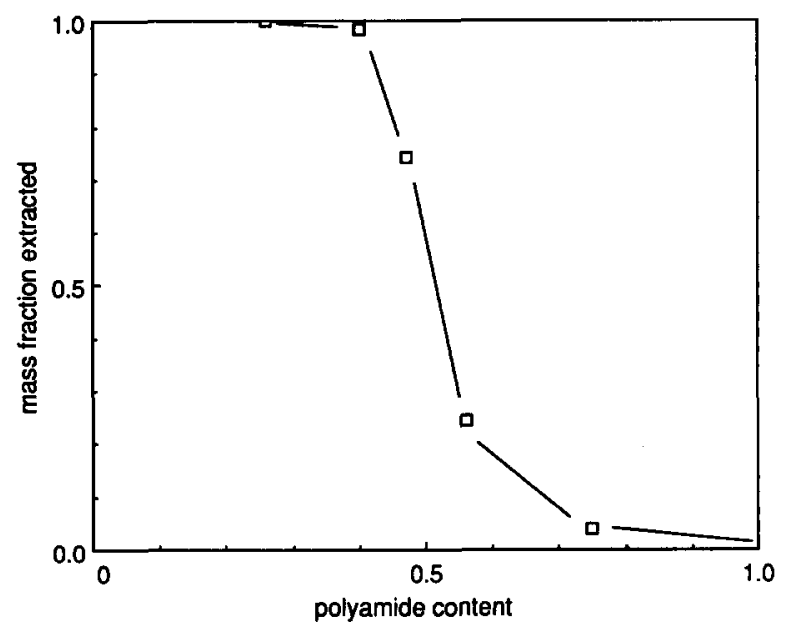

Figure 1 Soxhlet extraction of N46-PPOx copolymers with ethanol. The mass fraction of material extracted is plotted vs. the polyamide content $w_{\mathrm{PA}}$

Table 1 Characterization of as-prepared N46-PPOx copolymers

\begin{tabular}{|c|c|c|c|c|c|c|}
\hline Sample & $w_{\mathrm{PA}}$ & $\begin{array}{l}{[-\mathrm{COOH}]} \\
\left(\mathrm{mEq} \mathrm{g}^{-1}\right)\end{array}$ & $\begin{array}{l}{\left[-\mathrm{NH}_{2}\right]} \\
\left(\mathrm{mEq} \mathrm{g}^{-1}\right)\end{array}$ & $\begin{array}{l}\bar{M}_{\mathrm{n}} \\
\left(10^{3} \mathrm{~g} \mathrm{~mol}^{-1}\right)\end{array}$ & $\begin{array}{l}\eta_{\mathrm{inh}}{ }^{a} \\
\left(\mathrm{dl}^{-1} \mathrm{~g}^{-1}\right)\end{array}$ & $\begin{array}{l}\text { Ethanol- } \\
\text { extractable }\end{array}$ \\
\hline PA26 & 0.26 & - & - & - & 0.35 & 1.0 \\
\hline PA40 & 0.40 & 0.147 & 0.034 & 11.1 & 0.47 & 0.99 \\
\hline PA47 & 0.47 & - & - & - & 0.54 & 0.74 \\
\hline PA56 & 0.56 & - & - & - & 0.73 & 0.24 \\
\hline PA75 & 0.75 & 0.102 & 0.011 & 17.7 & 0.76 & 0.04 \\
\hline
\end{tabular}

a $1 \mathrm{~g} \mathrm{dl}^{-1}$ solution in $m$-cresol at $25^{\circ} \mathrm{C}$ 
further, but in similar experiments on N46-PTMO copolymers, the extract proved to be of high polyether content $^{18}$.

At a polyamide content of 0.4 , the N46-PPOx copolymer is almost fully extractable. This implies that most of the polyamide is extracted as well. Obviously the elastomer network is not fully developed. Either the chains are too short, or too few hard blocks are long enough to form crystals that are stable in a swollen network.

\section{Torsional modulus}

Figure 2 shows the storage moduli of the dry N46PPOx copolymers; the loss moduli are presented in Figure 3. Some data are collected in Table 2. In Figure 4 the glass transition temperature (taken to be the maximum in $G^{\prime \prime}$ here) is plotted vs. the polyamide content. It appears that the glass transition lies around $-15^{\circ} \mathrm{C}$ for low polyamide contents. This $T_{\mathrm{g}}$ value is $\sim 40^{\circ} \mathrm{C}$ higher than the $T_{\mathrm{g}}$ of PPOx homopolymer ${ }^{14}$; it is close, however, to the $T_{\mathrm{g}}$ of the liquid copolymer that was obtained from PPOx diamine and adipic acid (sample PA26). The $T_{\mathrm{g}}$ of the latter was determined on a sample of filter paper impregnated with the highly viscous liquid copolymer. This result shows that the introduction of amide bonds at short intervals along the chain strongly reduces the mobility of a PPOx chain.

With increasing polyamide content, $T_{\mathrm{g}}$ is displaced to higher temperatures, until at $75 \%$ polyamide two separate transitions can be distinguished. The temperature shift

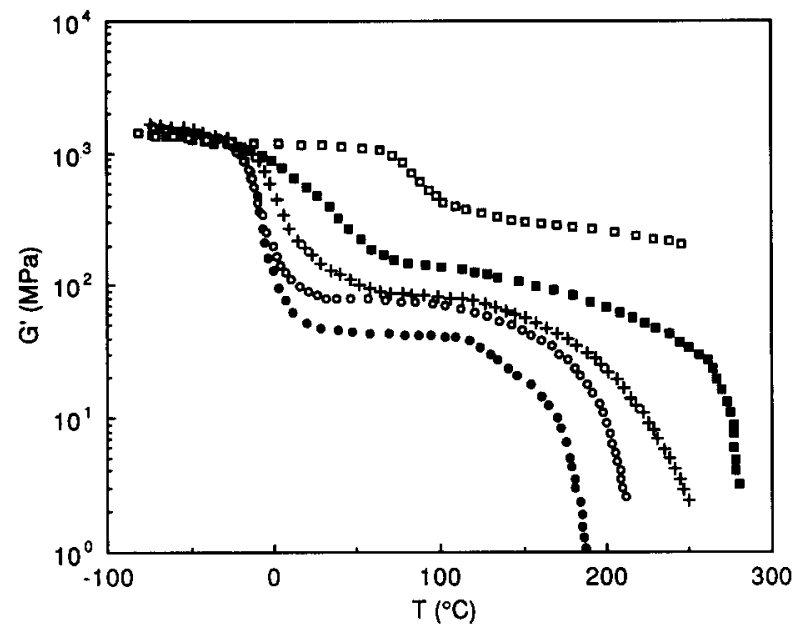

Figure 2 Torsional storage moduli of N46-PPOx copolymers of varying polyamide content $w_{\mathrm{PA}_{A}}$, as a function of temperature: (0) $w_{\mathrm{PA}}=0.40 ;(0) w_{\mathrm{PA}}=0.47 ;(+) w_{\mathrm{PA}}=0.56 ;$ (回) $w_{\mathrm{PA}}=0.75 ;(\square)$ $w_{\mathrm{PA}}=1.0$

Table 2 Torsional modulus data for N46-PPOx copolymers

\begin{tabular}{lcccr}
\hline Sample & $\begin{array}{l}T_{\mathrm{g}} \\
\left({ }^{\circ} \mathrm{C}\right)\end{array}$ & $\begin{array}{l}G^{\prime} \text { at } 20^{\circ} \mathrm{C} \\
(\mathrm{MPa})\end{array}$ & $\begin{array}{l}G^{\prime} \text { at } 100^{\circ} \mathrm{C} \\
(\mathrm{MPa})\end{array}$ & $\begin{array}{l}T_{\text {flow }} \\
\left({ }^{\circ} \mathrm{C}\right)\end{array}$ \\
\hline PA26 & -20 & - & - & -20 \\
PA40 & -12 & 50 & 40 & 170 \\
PA47 & -12 & 85 & 70 & 200 \\
PA56 & -3 & 170 & 80 & 220 \\
PA75 & 2,38 & 550 & 140 & 270 \\
Nylon-4,6 & 82 & 1100 & $400^{a}$ & $>270$ \\
\hline
\end{tabular}

${ }^{a} G^{\prime}$ at $100^{\circ} \mathrm{C}$ is close to $300 \mathrm{MPa}$ when extrapolated from the plateau range

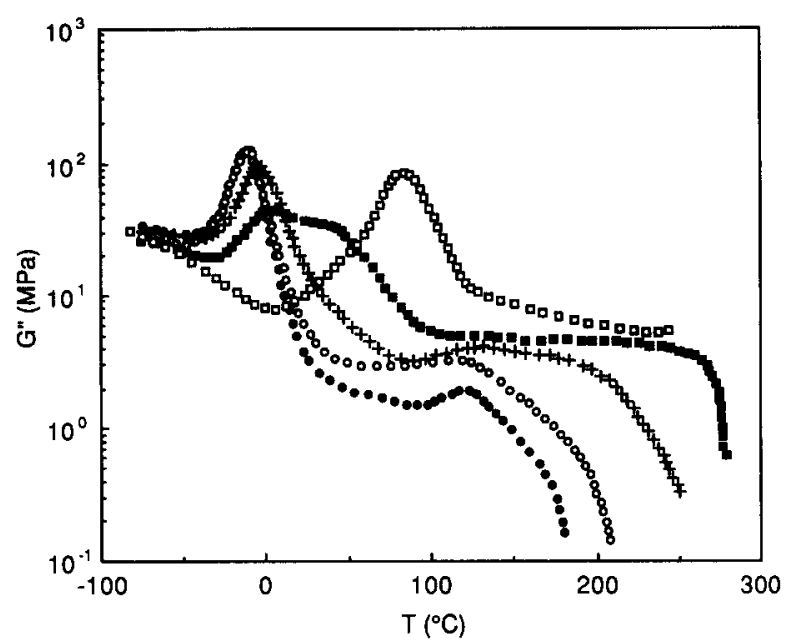

Figure 3 Torsional loss moduli of N46-PPOx copolymers of varying polyamide content $w_{\mathrm{PA}}$, as a function of temperature: $(\boldsymbol{O}) w_{\mathrm{PA}}=0.40$; (O) $w_{\mathrm{PA}}=0.47 ;(+) w_{\mathrm{PA}}=0.56 ;(\square) w_{\mathrm{PA}}=0.75 ;$ (口) $w_{\mathrm{PA}}=1.0$

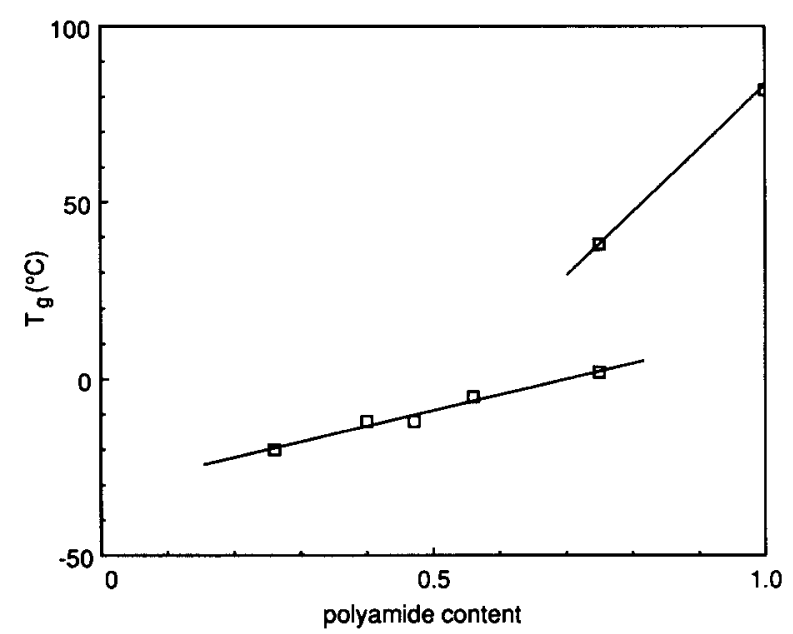

Figure 4 Glass transition temperatures of N46-PPOx copolymers as a function of polyamide content $w_{\mathrm{PA}} \cdot T_{\mathrm{g}}$ is defined as $\max \left(G^{\prime \prime}\right)$

results from the mixing of non-crystallizable polyamide blocks with the polyether blocks, so as to form a single amorphous phase. The peak splitting at higher polyamide content indicates partial segregation, but pure phases (consisting of one type of block only) are not formed.

As shown in Figure 2, the copolymers containing 47\% or more polyamide maintain a fairly constant value of the rubber modulus up to $150^{\circ} \mathrm{C}$, and the onset of flow occurs above $200^{\circ} \mathrm{C}$. These temperatures are still far from the melting point of nylon-4,6 $\left(\simeq 290^{\circ} \mathrm{C}\right)$, however. Copolymer sample PA75 begins to approach this value, but this material is no longer rubber-like.

\section{Differential scanning calorimetry}

D.s.c. results for as-prepared copolymers are presented in Figure 5 and in Table 3. After heating to $20^{\circ} \mathrm{C}$ above $T_{\mathrm{m}}$ and subsequent cooling at a rate of $10^{\circ} \mathrm{Cmin}^{-1}$, the melting points found in the second heating run are $10-15^{\circ} \mathrm{C}$ lower than those recorded during the first heating run of the as-prepared copolymer.

Sample PA56 exhibits an unexpectedly high melting point compared to sample PA47. Presumably, the postcondensation procedure has been an effective annealing treatment for sample PA56, with crystallization being a driving force for a block-length increase. 


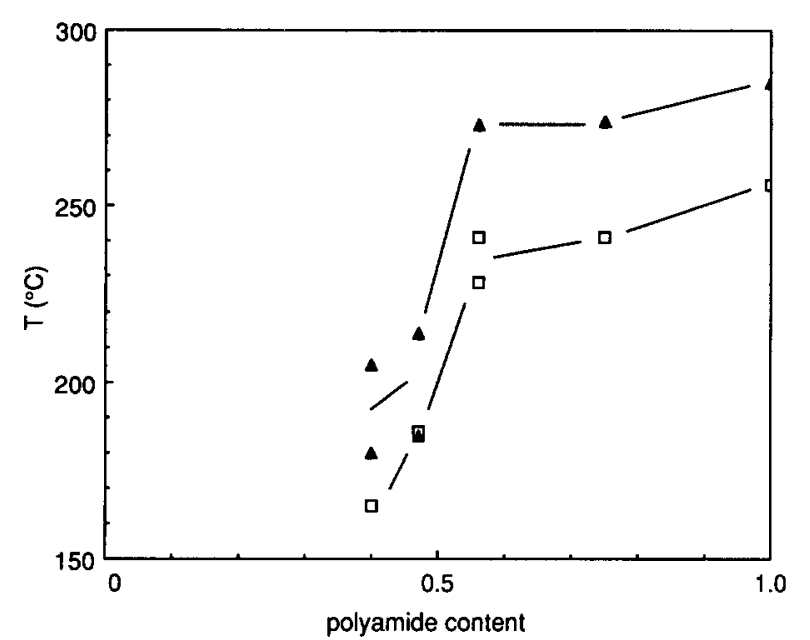

Figure 5 D.s.c. results for N46-PPOx copolymers of varying polyamide content $w_{\mathrm{PA}}:(\square)$ crystallization temperature; (A) melting temperature found in the second heating run

Table 3 Thermal data for N46-PPOx copolymers, obtained by d.s.c.

\begin{tabular}{llcll}
\hline Sample & $\begin{array}{l}T_{\mathrm{c}} \\
\left({ }^{\circ} \mathrm{C}\right)\end{array}$ & $\begin{array}{l}\Delta H_{\mathrm{m}}{ }^{a} \\
\left(\mathrm{Jg}^{-1}\right)\end{array}$ & $\begin{array}{l}\Delta H_{\mathrm{m}}, \mathrm{PA} \\
\left(\mathrm{Jg}^{-1} \mathrm{PA}\right)\end{array}$ & $\begin{array}{l}T_{\mathrm{m}}{ }^{a} \\
\left({ }^{\circ} \mathrm{C}\right)\end{array}$ \\
\hline PA40 & 165 & 1.9 & 4.8 & 180,205 \\
PA47 & 186 & 3.2 & 6.8 & 185,214 \\
PA56 & 241,228 & 14 & 25 & 273 \\
PA75 & 241 & 43 & 58 & 274 \\
Nylon-4,6 & 256 & 84 & 84 & 285 \\
\hline
\end{tabular}

${ }^{a}$ Values obtained in the second heating run

Table 3 lists the overall heats of fusion, $\Delta H_{\mathrm{m}}$, as well as the values of $\Delta H_{\mathrm{m}, \mathrm{PA}}$, which were calculated on the basis of the nylon-4,6 mass fraction of the copolymers. For the copolymers of low polyamide content, the values of both melting point and heat of fusion are low in comparison with nylon-4,6. In these softer copolymers crystallization is hampered, since the average number of repeat units in the hard blocks is much lower than five, the value for high-melting nylon-4,6 crystallites. In sample PA75 the average hard-block length is approximately five, too.

In Figure 6 the torsional storage modulus at $100^{\circ} \mathrm{C}$ is plotted as a function of the overall heat of fusion, which is of course a measure of the concentration of hard domains in the copolymer ${ }^{11}$.

\section{Wide-angle $X$-ray diffraction}

The crystal structure of nylon-4,6 was elucidated by Doeksen ${ }^{21}$, who has indexed many reflections. Using WAXD photography and densitometry we have concluded that the diffraction patterns of the copolymers are very similar to those of pure nylon-4,6. The interplanar distances of the stronger reflections are presented in Table 4.

A change in the relative intensity of the 100 and 010 reflections (Figure 7) suggests that the lateral aspect ratio (i.e. roughly perpendicular to the chain axis) of the crystallites in the copolymers differs from that in nylon4,6 . Our interpretation is that the growth of the planes containing the hydrogen bonds ( $a c$ planes) is much less hampered by the reduced length of the hard blocks than growth of the $b c$ planes. (Note that the densitometer curves are transmission curves, for which no conversion to optical density has been carried out.)

\section{Small-angle $X$-ray scattering}

The technique of small-angle $X$-ray scattering primarily provides us with two types of information, the first concerning phase dispersion (geometry) and the second characterizing phase composition (density). The degree of dispersion can be estimated from the scattering curve through the calculation of various length parameters with different meanings, such as the inhomogeneity length $l_{\mathrm{p}}$, the correlation length $l_{\mathrm{c}}$ and the long period $L$. The results for our N46-PPOx samples are collected in Table 4. The trend is similar for each of these parameters. Samples PA40 and PA47 appear to have a finer substructure than samples PA56 and PA75. This is in agreement with the d.s.c. experiments, which suggest a much larger harddomain (crystallite) size for the latter two copolymers. The long-period values for samples PA56 and PA75 are in the usual range for semicrystalline materials. One must

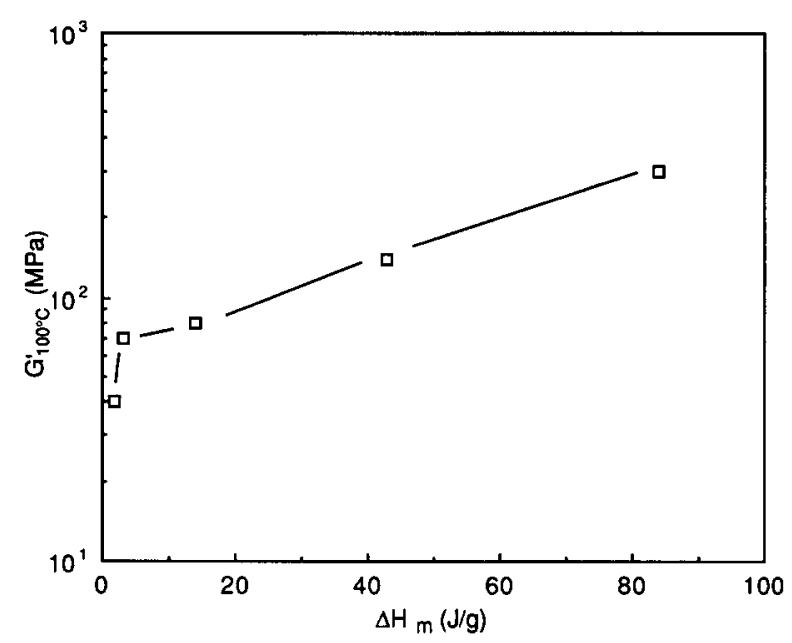

Figure 6 Torsional storage moduli at $100^{\circ} \mathrm{C}$ of N46-PPOx copolymers of varying polyamide content as a function of the heat of fusion $\Delta H_{\mathrm{m}}$ measured in the second d.s.c. heating run

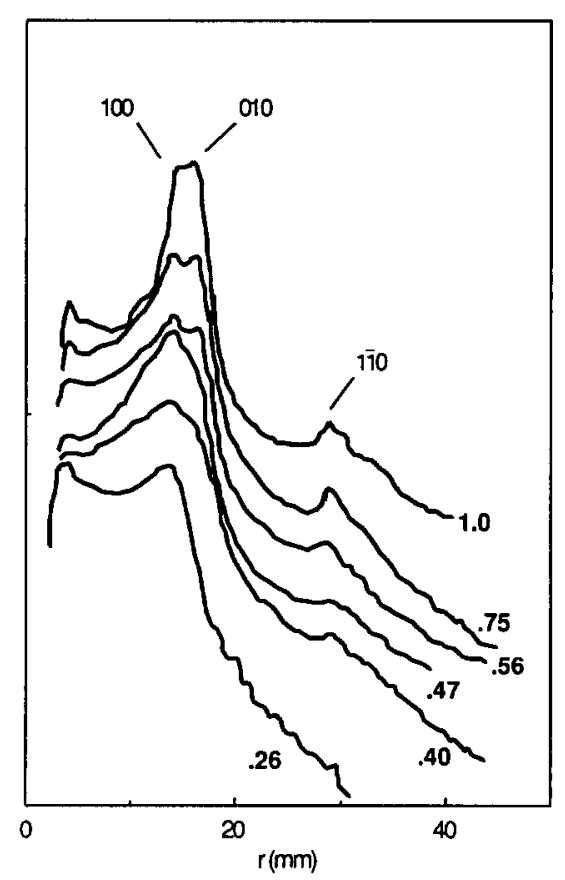

Figure 7 Wide-angle X-ray diffraction patterns of N46-PPOx copolymers of varying polyamide content. (The curves represent densitometer transmission data; they are arbitrarily displaced along the ordinate for comparison; $r$ is the radial distance on the film at a sample-to-film distance of $38.5 \mathrm{~mm}$ ) 
Table 4 X-ray data for N46-PPOx copolymers

\begin{tabular}{|c|c|c|c|c|c|c|c|}
\hline Sample & $\begin{array}{c}d_{h k l}^{a} \\
(\mathrm{~nm})\end{array}$ & $\begin{array}{l}d_{010} \\
(\mathrm{~nm})\end{array}$ & $\begin{array}{l}d_{100} \\
(\mathrm{~nm})\end{array}$ & $\begin{array}{l}L \\
(\mathrm{~nm})\end{array}$ & $\begin{array}{l}l_{c} \\
(\mathrm{~nm})\end{array}$ & $\begin{array}{l}l_{\mathrm{p}} \\
(\mathrm{nm})\end{array}$ & $\overline{\Delta \rho^{2}}$ \\
\hline PA26 & - & - & $0.44 \pm 0.01^{c}$ & - & - & -- & - \\
\hline PA40 & $0.238 \pm 0.004$ & $0.380 \pm 0.008$ & 0.44 & 6.4 & 2.4 & 1.6 & 0.185 \\
\hline PA47 & 0.236 & 0.385 & 0.44 & 6.7 & 2.6 & 1.7 & 0.162 \\
\hline PA56 & 0.238 & 0.377 & 0.44 & 16.7 & 4.4 & 2.2 & 0.193 \\
\hline PA75 & 0.237 & 0.375 & 0.44 & 11.9 & 4.4 & 2.7 & 0.158 \\
\hline Nylon-4,6 & 0.237 & 0.387 & 0.41 & - & - & - & - \\
\hline Nylon $-4,6^{d}$ & - & 0.382 & 0.43 & - & - & - & - \\
\hline
\end{tabular}

a Overlapping reflections 200,120 and 110

${ }^{b}$ Mean-square electron density difference, in $10^{-2}$ (mol electron $\left.\mathrm{cm}^{-3}\right)^{2}$

c Amorphous halo

"Data by Doeksen ${ }^{21}$

realize that the thickness of the crystalline domain will be smaller than $L$, and the $l_{\mathrm{p}}$ values (which equal four times the volume-to-surface ratio for randomly dispersed particles) suggest that the domains are much smaller indeed.

Absolute values for the scattering power, $\overline{\Delta \rho^{2}}$, of the samples are also presented in Table 4. Interpretation of these values will not be pursued here, since the calculation of the degree of phase separation requires precise knowledge of the densities of the pure phases as well as their volume fractions. Sufficiently accurate density values for the polyether and amorphous nylon-4,6 are lacking, however.

Analysis of the 'tail' of the SAXS curves did not suggest the existence of a transition layer exceeding $1 \mathrm{~nm}$ in thickness between hard and soft phases.

\section{CONCLUSIONS}

This work has shown the feasibility of preparing thermoplastic elastomers (TPE) based on polyamide- 4,6 and a polyether soft segment, in this case poly(propylene oxide) (PPOx). Because of its intrinsically high melting temperature and its strong tendency to crystallization, polyamide4,6 is well suited to be the hard component in multiblock copolymers, even those with very short segments.

The incorporation of PPOx of molar mass 2090 led to inhomogeneous products. The underlying cause is thought to be phase separation of the reaction mixture ('melt phasing'), which eventually gives rise to a crude microstructure in the solid state.

The solids obtained with PPOx of molar mass 430 look more promising, but the number-average molar mass is still low $(<20000)$.

If one assumes random copolymerization, the average number of repeat units in the polyamide hard blocks of the softer materials is so small $(<2)$ that only a very broad distribution of block lengths will allow crystallization to occur at all. This is in agreement with our finding that the heat of fusion of the N46-PPOx copolymers, with respect to the polyamide content, is low. A low heat of fusion implies the presence of a considerable amount of uncrystallized polyamide blocks. Owing to their restricted length, these polyamide segments do not segregate from the polyether phase but rather mix with the latter. This was inferred from the appearance of one, rather broad, glass transition in torsional modulus experiments.

The glass transition is found at temperatures considerably higher than the $T_{\mathrm{g}}$ of pure PPOx $\left(\simeq-60^{\circ} \mathrm{C}\right)$. The poly(ether amide) of lowest possible polyamide content, synthesized from oligomer PPOx diamine and adipic acid, already has its $T_{\mathrm{g}}$ at $-20^{\circ} \mathrm{C}$. This shows that the high $T_{\mathrm{g}}$ values are to be attributed to the restricted length of the PPOx chains between amide bonds. This has a stiffening effect on the chain and moreover it introduces a certain degree of compatibility with polyamide- 4,6 blocks.

For this TPE, the lower bound of the rubber region is raised when the polyamide content is increased. Resorting to a somewhat higher molar mass, e.g. 1000, of the PPOx diamine oligomer may improve on this, promoting crystallization and reducing compatibility in the amorphous phase. This will lower the glass transition temperature and raise the melting point, and thus extend the service temperature range of this poly(ether amide).

\section{REFERENCES}

1 Bayer, O., Rinke, H., Siefken, W., Ortner, L. and Schild, H., Ger. Pat. 728981, 1937

2 Coleman, D. J. Polym. Sci. 1954, 14, 15

3 Bonart, R. J. Macromol. Sci.-Phys. (B) 1968, 2, 115

4 Van Bogart, J. W. C., Gibson, P. E. and Cooper, S. L. J. Polym. Sci., Polym. Phys. Edn. 1983, 21, 65

5 Meckel, W., Goyert, W. and Wieder, W. in 'Thermoplastic Elastomers' (Eds. N. R. Legge, G. Holden and H. E. Schroeder), Hanser, Munich, 1987, Ch. 2

6 Tyagi, D., Yilgör, I., McGrath, J. E. and Wilkes, G. L. Polymer 1984, 25, 1807

7 Cella, R. J. J. Polym. Sci. Symp. 1973, 42, 727

8 Lilaonitkul, A., West, J. C. and Cooper, S. L. J. Macromol. Sci.-Phys. (B) 1976, 12, 563

9 Bandara, U., Dröscher, M. and Thomas, E. L. Colloid Polym. Sci. 1984, 262, 538

10 Adams, R. K. and Hoeschele, G. K. in 'Thermoplastic Elastomers' (Eds. N. R. Legge, G. Holden and H. E. Schroeder), Hanser, Munich, 1987, Ch. 8

11 Wegner, G. in 'Thermoplastic Elastomers' (Eds. N. R. Legge, G. Holden and H. E. Schroeder), Hanser, Munich, 1987, Ch. 12, Sec. 5

12 Perego, G., Cesari, M. and Della Fortuna, G. J. Appl. Polym. Sci. 1984, 29, 1141

13 Goldbach, G., Kita, M., Meyer, K. and Richter, K. P. Prog Colloid Polym. Sci. 1986, 72, 83

14 Yui, N., Tanaka, J., Sanui, K. and Ogata, N. Makromol. Chem. 1984, 185, 2259

15 Nelb, R. G., Chen, A. T. and Onder, K. in 'Thermoplastic Elastomers' (Eds. N. R. Legge, G. Holden and H. E. Schroeder), Hanser, Munich, 1987, Ch. 9A

16 Deleens, G. in 'Thermoplastic Elastomers' (Eds. N. R. Legge, G. Holden and H.E. Schroeder), Hanser, Munich, 1987, Ch. 9B

17 Gaymans, R. J., Van Utteren, T. E. C., Van den Berg, J. W. A and Schuyer, J.J. Polym. Sci., Polym. Chem. Edn. 1977, 15, 537

18 Gaymans, R. J., Schwering, P. and De Haan, J. L. Polymer $1989,30,974$

19 Vonk, C. G. J. Appl. Crystallogr. 1975, 8, 340

20 Frensdorff, H. K. Macromolecules 1971, 4, 369

21 Doeksen, D. K., unpublished results, University of Twente, 1981 